\title{
Influence of the porosity structure of road concrete on its durability
}

\author{
Denis Smirnov ${ }^{1[000-0001-7787-4265]}$, Sergey Stepanov ${ }^{* 1[0000-0003-4926-8537]}$, Ruslan Garipov 2[0000-0002-5894-9804], \\ Timur Garayev ${ }^{3}$, and Tagir Sungatullin ${ }^{4}$ \\ ${ }^{1}$ Kazan State University of Architecture and Engineering, 420043 Kazan, Russia \\ ${ }^{2}$ LLC «Project Bureau TechStroy», 420087 Kazan, Russia \\ ${ }^{3}$ JSC «Kazmetrostroy», 420127 Kazan, Russia \\ ${ }^{4} \mathrm{LLC}$ «Road bulding fnd repair», 423820 Kazan, Russia
}

\begin{abstract}
Cement-concrete pavements of roads and airfields are the most durable type of pavement. The design service life of cement-concrete pavements is $40-50$ years, in Russia this period is $20-25$ years, and for asphalt-concrete pavements is $10-15$ years. The real, actual overhaul period of asphalt concrete pavements, is much lower than the design one (according to the Federal Road Agency of Russia «Rosavtodor», on average, 3-5 years or even less), therefore, work aimed at increasing the durability of cementconcrete pavements is of particular relevance. The main technical parameters of road concrete that characterize its durability are compressive strength, flexural tensile strength, water absorption and others. The most important parameter is the frost resistance of concrete, which is primarily influenced by the structure of the pore space. This paper shows the way of obtaining concretes based on aggregates, the frost resistance of which is lower than the frost resistance of the resulting concrete.
\end{abstract}

Keywords. Concrete, porosity, concrete roads, frost resistance, strength.

\section{Introduction}

Quality improvement of road pavements has been repeatedly emphasized at the level of the Government of Russian Federation (RF) and its subjects, the «Strategy for the development of the building materials industry for the period until 2020 and for the future until 2030», as well as the «Action Plan for the implementation of the Strategy» have been developed. These documents set the task of increasing the share of cement concrete roads construction in Russia up to $50 \%$ by 2030. Currently, the main technical standards on design of concrete pavements valid in RF are:

- SP 34.13330.2012 «Automobile roads»;

- GOST 33100-2014 «Automobile roads of general use. Rules of roads projecting»;

- GOST 26633-2015 «Heavy-weight and sand concretes. Specifications»;

- GOST 31384-2017 «Protection of concrete and reinforced concrete structures against corrosion. General technical requirements»;

- GOST 32960-2014 «Automobile roads of general use. Traffic load models, application of the load models».

*Corresponding author: seregins2@yandex.ru 
It should be noted that the requirements for raw materials of concretes based on them, set out in these documents, are very contradictory. So, according to the requirements of technical standards, the frost resistance level of a large aggregate must be not less than the frost resistance level of concrete, which significantly limits the availability of the raw material base. The highest requirements for the technical properties of concrete are given in GOST 31384-2017, according to which the compressive strength class of concrete should be B35, frost resistance level $\mathrm{F}_{2} 200$, while there are no requirements for flexural tensile strength, which is a very important indicator for concretes of this purpose. In SP 34.13330.2012, the minimum design classes of concrete for compressive strength are B30, and flexural tensile strength $\mathrm{B}_{\mathrm{tb}} 4,0$. The minimum design frost resistance level is $\mathrm{F}_{2} 150$.

In general, higher requirements are imposed on concretes for road and airfield pavements and base courses compared to concretes for hydraulic engineering or general construction [1-3]. This is due to more difficult operating conditions of road concrete [4]. The synergistic impact of dynamic loads and atmospheric factors on pavement, especially in the presence of anti-icing solutions on it, contributes to intensification of destructive processes in concrete [5-7]. In this case, the most important parameter for preserving the operational properties of concrete will be the indicator of its frost resistance level $[8,9]$. In a series of works [10-16], the authors pay great attention to the quality of materials in the construction of cementconcrete roads, industrial and civil structures.

The frost resistance of concrete, first of all, will be influenced by the quality of the materials used and the structure of the pore space. So, according to GOST 26633-2015, the introduction of air-entraining additives into the composition of road concrete is mandatory. At the same time, the requirements in considered technical standards for the amount of entrained air also differ from each other, but in general it ranges from 4.0 to $7.0 \%$.

It is well known $[17,18]$ that ability of concrete to resist destruction during repeated freezing and thawing in a water-saturated state is due to the presence in its structure of closed «reserve» pores, unfilled with water. As a result of diffusion movement of water during its transition from one state of aggregation to another, the pressure from growing ice crystals on the walls of open pores decreases. A lot of work is devoted to the study of the pore space by various methods [19-21].

Depending on size in body of concrete, the pores can be divided into three groups:

- $0,1 \div 1,6 \mathrm{~nm}$ in size - gel pores;

$-1,6 \div 50 \mathrm{~nm}$ in size - contraction pores;

$-50 \mathrm{~nm}$ - capillary pores.

Gel pores are characterized by minimum permeability of concrete for liquids and gases [22]. The transfer of liquid phase in gel pores is possible only by the mechanism of molecular diffusion. Water in the gel pores does not freeze during the operation of concrete and reinforced concrete structures, which is explained by their size, content of electrolyte additives in pore fluid of concrete.

Capillary pores of concrete can be represented as a part of the volume of cement paste water not filled with cement hydration products [23]. Any concrete has micro-capillaries. They are capable of capillary condensation of moisture, which makes the materials hygroscopic. Macro-capillaries with a radius greater than 0.1 microns (usually up to 10 microns) are filled with water only in direct contact with it. Capillary pores are the main defect in the structure of the cement stone.

The freezing point of water in a capillary-porous body depends on the size of the capillaries. For example, in capillaries with a diameter of $1.57 \mathrm{~mm}$, water freezes at $-6.4^{\circ} \mathrm{C}$; $0.15 \mathrm{~mm}$ at $-14.6^{\circ} \mathrm{C} ; 0.06 \mathrm{~mm}-18^{\circ} \mathrm{C}$. In pores with a diameter of less than $0.001 \mathrm{~mm}$, water practically does not freeze; it acquires the properties of a pseudo-solid body. 
A vacuum is created in the pores of concrete due to contraction, and they are filled, depending on the hardening conditions, with air or water. It is customary to consider the contraction volume not as an independent type of pore, but as a part of capillary porosity.

Conditionally closed pores of concrete include air bubbles in cement stone and concrete. The total pore volume, their size, number and specific surface area can be controlled by the introduction of air-entraining or gas-forming additives. Air pores obtained by introducing airentraining additives into the concrete mix significantly change the structure of the cement stone. The number of air pores in $1 \mathrm{~cm}^{3}$ of cement stone can reach one million, and the surface of these pores is $200-250 \mathrm{~cm}^{2}$. Through this surface, excess water enters the air pores, which is displaced from the capillaries when the concrete is frozen. Only sufficiently small air pores less than $0.5-0.3 \mathrm{~mm}$ in size have a protective effect.

As a criterion for assessing the effectiveness of the protective action of air pores in concrete so-called «distance factor» proposed by T. Powers [24] are widely used. For its calculation, it is assumed that in the cement stone there is a certain idealized system of identical air pores located at an equal distance from each other. In this case, the farthest points from the air pore are the points of the cement stone lying in the corners of the cube. The distance from such a point to the pore edge (along the diagonal of the cube) is the distance factor (FR) determined by the formula (1):

$$
F R=\frac{30}{\lambda} *\left[1.4 *\left(\frac{V_{c s}}{V_{a p}}+1\right)^{\frac{1}{3}}-1\right]
$$

where $V_{c s}$ - volume of cement stone, $\lambda$ - specific surface area of the air pore system, $\mathrm{cm}^{2} / \mathrm{cm}^{3}$, $V_{a p}$ - volume of air pores in concrete. In a microscopic study of thin sections of concrete, the FR is determined by measuring the length of the chords of the pores and their number along a range of lines. Based on the measurement results, the volume of air pores and their specific surface area are calculated. Simplistically, the distance factor can be represented as the average distance between air pores in a cement stone. It is believed that to obtain concretes of high frost resistance, the distance factor should not exceed $0.2-0.25 \mathrm{~mm}$.

It should be noted that it characterizes the parameters of the air pore system in the cement stone, which protects these pores. This is another advantage of the distance factor over the volume of air, which is related to the volume of the concrete mix.

The distance factor, like «protected volume» of the cement stone, is calculated from the specific surface area of air pores. The efficiency of air pores will be the greater, the higher their specific surface area is, therefore, the less is thickness of cement stone layer when it is evenly distributed over this surface. The specific surface area is a qualitative characteristic of air pores, since it does not take into account their content. In this regard, it loses to the distance factor.

In works of Batrakov V.G. and Kuntsevich V.O. [25, 26] about optimal parameters of a system of conditionally closed pores in frost-resistant concretes, it was found that the permissible value of the average size of conditionally closed pores, calculated from the condition of ensuring high strength and frost resistance, and the permissible value of the minimum diameter of conditionally closed pores $d_{\min }$ (2), allows, in the first approximation, to assess optimal distribution of conditionally closed pores by their sizes:

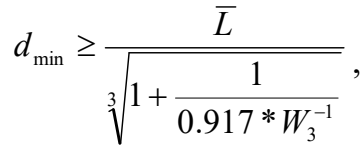

where $\bar{L}$-distance factor, $W_{3}$ - the amount of water frozen in the capillaries of the cement stone, determined by the value of the water-cement ratio $(W / C)$ and degree of hydration of cement stone. 
Thus, an increase in the content of cement stone in concrete requires not only a finely dispersed, but also a more uniform system of conditionally closed pores. More severe freezing regimes, requiring a decrease in the distance factor to ensure high frost resistance, shift the optimal distribution of conditionally closed pores towards smaller sizes and narrow them. A decrease in $W / C$ expands the range of possible fluctuations in the size of conditionally closed pores.

The most important operational factors for concrete, in addition to the number of freezing and thawing cycles, include degree of water saturation and concrete freezing temperature. A decrease in strength of concrete after freezing and thawing is observed only when its water saturation is above a certain value, which, in turn, is associated with value of negative temperature. The value of the critical water saturation can be achieved not only when concrete is saturated with water before freezing, but also as a result of redistribution of pore water in freezing concrete in the form of steam. The water saturation of concrete increases in the presence of salts.

The purpose of this work is to investigate the possibility of increasing the frost resistance of cement concretes (up to grade $\mathrm{F}_{2} 200$ ) for road construction based on crushed stone and gravel of grade F150 by directionally regulating its pore structure with a complex of airentraining and plasticizing additives.

\section{Materials and methods}

As a binder for the production of concrete was used Portland cement 500-DO-N of Mordovcement JSC.

Table 1. Physical and mechanical properties of Portland cement.

\begin{tabular}{|c|c|c|c|c|c|c|c|}
\hline $\begin{array}{c}\text { Normal } \\
\text { density of } \\
\text { cement }\end{array}$ & \multicolumn{2}{|c|}{$\begin{array}{c}\text { Setting time, } \\
\text { hour: min }\end{array}$} & \multicolumn{2}{|c|}{ Compressive strength, MPa } & \multirow{2}{*}{$\begin{array}{c}\text { Product } \\
\text { size }\end{array}$} & \multirow{2}{*}{ Soundness } \\
\cline { 2 - 6 } paste, \% & Beginning & Ending & steaming & 3 days & $\mathbf{2 8 ~ d a y s}$ & & \\
\hline $24.6-26.4$ & $3: 15$ & $4: 15$ & 43.3 & 36.3 & 56.5 & 97.8 & OK \\
\hline
\end{tabular}

Table 2. Chemical composition of cement.

\begin{tabular}{|c|c|c|}
\hline $\begin{array}{c}\text { Content of } \\
\text { sulfur oxide (VI) } \mathrm{SO}_{3}\end{array}$ & $\begin{array}{c}\text { Fraction of alkalic oxides } \mathbf{R}_{2} \mathbf{O} \\
\text { expressed as } \mathrm{Na}_{2} \mathbf{O}\end{array}$ & $\begin{array}{c}\text { Content of } \\
\text { chloride ion } \mathbf{C l}^{-}\end{array}$ \\
\hline 3.00 & 0.79 & 0.019 \\
\hline
\end{tabular}

Table 3. Chemical and mineralogical composition of hard-burned brick.

\begin{tabular}{|c|c|c|c|c|}
\hline $\begin{array}{c}\text { Tricalcium } \\
\text { silicate } \\
\mathbf{C}_{3} \mathbf{S}\end{array}$ & $\begin{array}{c}\text { Dicalcium } \\
\text { silicate } \\
\mathbf{C}_{2} \mathbf{S}\end{array}$ & $\begin{array}{c}\text { Tricalcium } \\
\text { aluminate } \\
\mathbf{C}_{3} \mathbf{A}\end{array}$ & $\begin{array}{c}\text { Tetracalcium } \\
\text { alumoferrite } \\
\mathbf{C}_{4} \mathbf{A F}\end{array}$ & $\begin{array}{c}\text { Magnesium } \\
\text { oxide } \\
\text { MgO }\end{array}$ \\
\hline 62.67 & 14.18 & 6.54 & 13.60 & 1.27 \\
\hline
\end{tabular}

As a coarse aggregate, the study used gravel with characteristics M800-1000 and $\mathrm{F}_{1} 150$, as well as crushed stone made of this gravel.

The following additives were used as concrete modifiers:

- air-entraining additive Master Air based on surfactants, in a dosage of 0.1 to $0.6 \%$;

- plasticizer additive Master Glenium based on polycarboxylate ester, in a dosage of 0.2 to $0.9 \%$.

Concrete formulations were made from an optimized grain ratio of inert materials using modifiers in various combinations. The compositions are shown in Table 4. 
Table 4. Concrete compositions.

\begin{tabular}{|c|c|c|c|c|c|}
\hline $\begin{array}{c}\mathbf{m i x} \\
\text { № }\end{array}$ & $\begin{array}{c}\text { Cement } \\
\text { weight, } k g\end{array}$ & $\begin{array}{c}\text { Mass of inert } \\
\text { aggregates, kg }\end{array}$ & $\begin{array}{c}\text { Coarse } \\
\text { aggregate type }\end{array}$ & Additive type & $\begin{array}{r}\text { Additive } \\
\text { dosage, } \%\end{array}$ \\
\hline \multirow{2}{*}{1} & \multirow{14}{*}{375} & \multirow{14}{*}{1750} & Cruched rravel & Master Air & 0.3 \\
\hline & & & Crushed gravel & Master Glenium & 0.6 \\
\hline \multirow{2}{*}{2.1} & & & Crushed gravel & Master Air & 0.6 \\
\hline & & & Gravel & Master Glenium & 0.6 \\
\hline \multirow{2}{*}{2.2} & & & Crushed gravel & Master Air & 0.6 \\
\hline & & & Gravel & Master Glenium & 0.6 \\
\hline \multirow{2}{*}{3.1} & & & Crushed gravel & Master Air & 0.6 \\
\hline & & & Gravel & Master Glenium & 0.2 \\
\hline \multirow{2}{*}{3.2} & & & Crushed gravel & Master Air & 0.6 \\
\hline & & & Gravel & Master Glenium & 0.2 \\
\hline \multirow{2}{*}{4.1} & & & Crushed gravel & Master Air & 0.1 \\
\hline & & & Gravel & Master Glenium & 0.9 \\
\hline \multirow{2}{*}{4.2} & & & Crushed gravel & Master Air & 0.1 \\
\hline & & & Gravel & Master Glenium & 0.9 \\
\hline
\end{tabular}

Frost resistance was assessed by the third method at low temperatures $\left(-50^{\circ} \mathrm{C}\right)$ in a saline solution of sodium chloride (GOST 10060-2012).

The pore structure of concrete was studied by X-ray volumetric scanning of one dry sample from each series on a phoenix/X-ray industrial tomograph with a volume resolution of $0.1 \mathrm{~mm}$ in each direction. This method is widely used in the study of building materials [27, 28].

The paper presents the results of studying the structure and mechanical properties of road concrete prepared on gravel and crushed stone from gravel. The samples were made with different air entrainment conditions and, as a consequence, with different types of porosity.

The processing of the results of X-ray volumetric scanning was carried out by deriving the following diagrams for each series:

1. «Pore diameter - pore surface area». An indicator similar to that designated above. Accepted for analysis to compare the degree of influence on frost resistance;

2. «Pore diameter-pore compactness». The position of each point on the diagram corresponds to a paired characteristic - the diameter of the sphere described around the pore and the ratio of the pore volume to the volume of the sphere described around it. The diagram is accepted for analysis from the point of view of evaluating the approximation of pore shapes to a form that provides the possibility of ice expansion in the dimensions of pores partially filled by water;

3. «Pore diameter - pore volume». It is accepted for analysis as an indicator of the efficiency of pore distribution in sample, which minimizes the distance factor, which directly affects the frost resistance level.

\section{Results and discussion}

A series of samples was made on gravel mixes and on mixes of crushed stone from gravel. Concrete strength class B35. The test results of some mixes are shown in the table 5 .

The test results given in the table show that it is possible to obtain concretes that satisfy requirements of technical standards for strength and frost resistance using aggregates, with frost resistance level lower than that of the resulting concrete. As can be seen from the table, almost all mixes have a frost resistance level of $\mathrm{F}_{2} 200$ and higher, with the exception of mix 4.

Mix 4 has an air-entraining additive content of $0.1 \%$, as a result of which concretes with low frost resistance were obtained. An increase in the dosage of the air-entraining additive (mix 2 and 3) to $0.6 \%$ allows an increase in frost resistance up to F2300, but leads to a decrease in strength characteristics. An increased amount of superplasticizer of $0.9 \%$ (mix 4$)$ 
allows to increase the strength of concrete, but negatively affects frost resistance. As a result of the optimization of the air-entraining and superplasticizing additives, a composition (composition 1) has been developed, which has high frost resistance $\left(\mathrm{F}_{2} 300\right)$ and high strength characteristics (60.8 MPa).

Table 5. Frost resistance and strength characteristics of concrete.

\begin{tabular}{|c|c|c|c|c|c|c|}
\hline \multirow[b]{2}{*}{$\underset{\operatorname{mix}}{\text { № }}$} & \multirow{2}{*}{$\begin{array}{c}\text { Forst } \\
\text { resistance } \\
\text { level } / \text { numb } \\
\text { er of cycles }\end{array}$} & \multirow[b]{2}{*}{$\begin{array}{l}\text { Loss of } \\
\text { mass, \% }\end{array}$} & \multirow[b]{2}{*}{$\begin{array}{l}\text { GOST } 10060 \\
\text { requirements, \% }\end{array}$} & \multicolumn{2}{|c|}{$\begin{array}{c}\text { Compression } \\
\text { strength, MPa }\end{array}$} & \multirow[b]{2}{*}{$\begin{array}{c}\text { Design strength, } \\
\mathrm{MPa}\end{array}$} \\
\hline & & & & 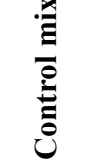 & 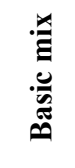 & \\
\hline 1 & $\mathrm{~F}_{2} 300 / 37$ & 0.75 & $<2$ & 67.53 & 60.8 & $\begin{array}{r}X_{\min }^{l}=57.5 ; \\
X_{\text {min }}^{l l}=53.5 \\
X^{l l}{ }_{\text {min }} \geq X_{\text {min }}^{l} \cdot 0.9 \\
53.5>57.5 \cdot 0.9=51.8\end{array}$ \\
\hline 2.1 & $\mathrm{~F}_{2} 200 / 20$ & 0.66 & $<2$ & 53.5 & 49.3 & $\begin{array}{r}X_{\text {min }}^{l}=49.9 ; \\
X_{\text {min }}^{l l}=45.6 \\
X_{\text {min }}^{l l} \geq X_{\text {min }}^{l} \cdot 0.9 \\
45.6>49.9 \cdot 0.9=44.95\end{array}$ \\
\hline 2.2 & $\mathrm{~F}_{2} 300 / 37$ & 1.29 & $<2$ & 56.1 & 39.0 & $\begin{array}{r}X_{\min }^{l}=54.4 \\
X_{\text {min }}^{l l}=31.4 \\
X_{\text {min }}^{l l} \geq \mathrm{X}_{\min }^{1} \cdot 0.9 \\
31.4<54.4 \cdot 0.9=49.0\end{array}$ \\
\hline 3.1 & $\mathrm{~F}_{2} 200 / 37$ & 1.15 & $<2$ & 50.1 & 47.6 & $\begin{array}{r}X_{\min }^{l}=46.9 ; \\
X_{\text {min }}^{l l}=45.5 \\
X_{\text {min }}^{l l} \geq X_{\min }^{1} \cdot 0.9 \\
45.5>46.9 \cdot 0.9=42.19\end{array}$ \\
\hline 3.2 & $\mathrm{~F}_{2} 300 / 37$ & 1.78 & $<2$ & 52.9 & 40.1 & $\begin{array}{r}X_{\min }^{l}=48.9 ; \\
X_{\text {min }}^{l l}=34.5 \\
X_{\text {min }} \geq X_{\text {min }}^{l} \cdot 0.9 \\
34.5<48.9 \cdot 0.9=44.0\end{array}$ \\
\hline 4.1 & $\mathrm{~F}_{2} 150 / 20$ & 0.45 & $<2$ & 53.5 & 48.5 & $\begin{array}{r}X_{\text {min }}^{l}=48.4 ; \\
X_{\text {min }}^{l l}=46.0 \\
X^{l l} \text { min } \geq X_{\text {min }}^{1} \cdot 0.9 \\
46,0>48,4 \cdot 0,9=43.6\end{array}$ \\
\hline 4.2 & $\mathrm{~F}_{2} 200 / 20$ & 0.66 & $<2$ & 53.4 & 44.8 & $\begin{array}{r}X_{\min }^{l}=46.4 \\
X_{\text {min }}^{l l}=34.4 \\
X_{\text {min }} \geq X_{\text {min }}^{l} \cdot 0.9 \\
34.4<46.4 \cdot 0.9=41.8\end{array}$ \\
\hline
\end{tabular}

Fig. 1-5 show the study results of the pore structure of the composition of concrete No. 1 . Based on the analysis of an array of similar data, the authors propose the use of a special algorithm that allows, on the basis of an effective combination of technological parameters, to design compositions of road concretes with increased frost resistance and predict their properties. 


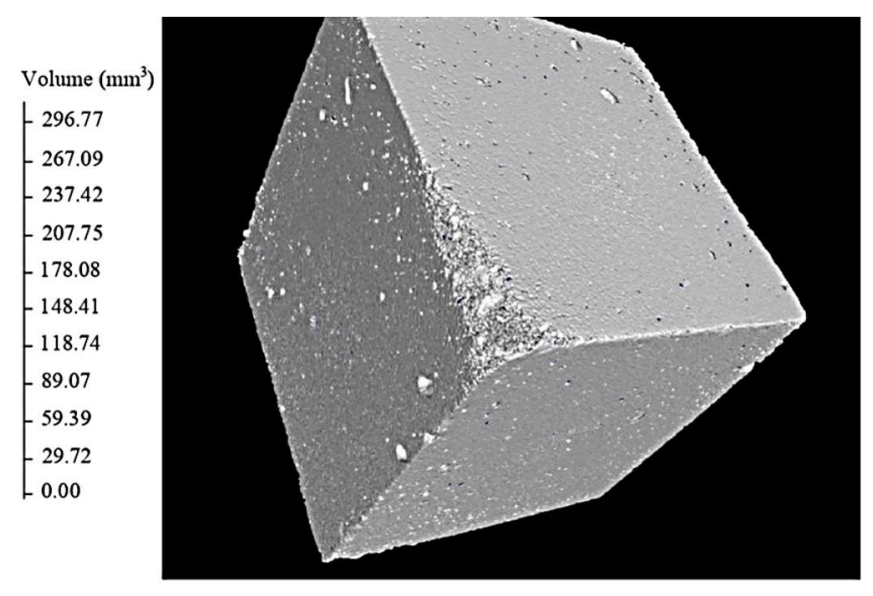

Fig. 1. General view of the sample and position of scanning planes.

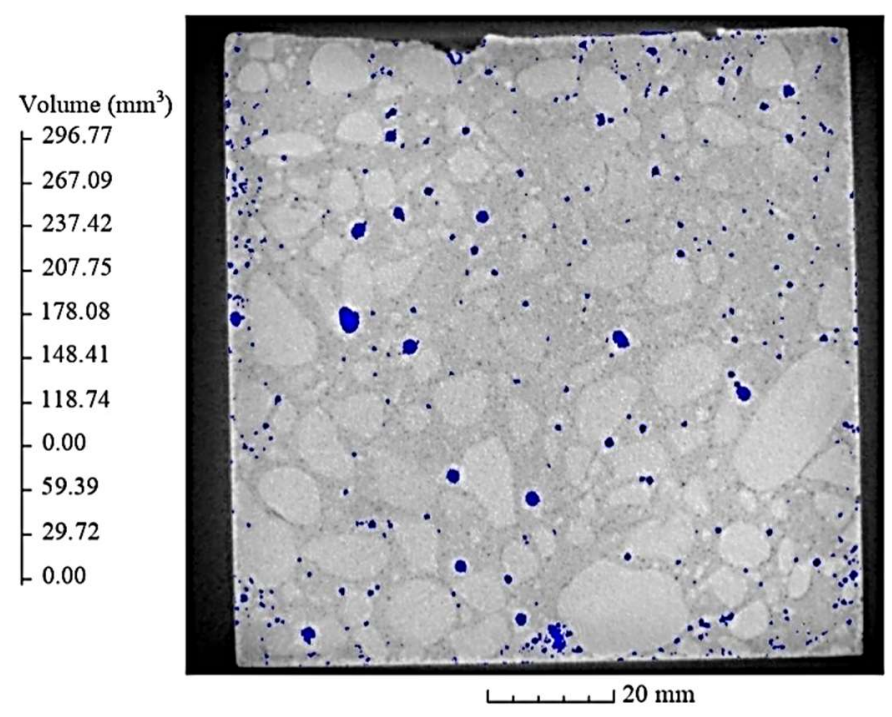

Fig. 2. View on the scanning plane.

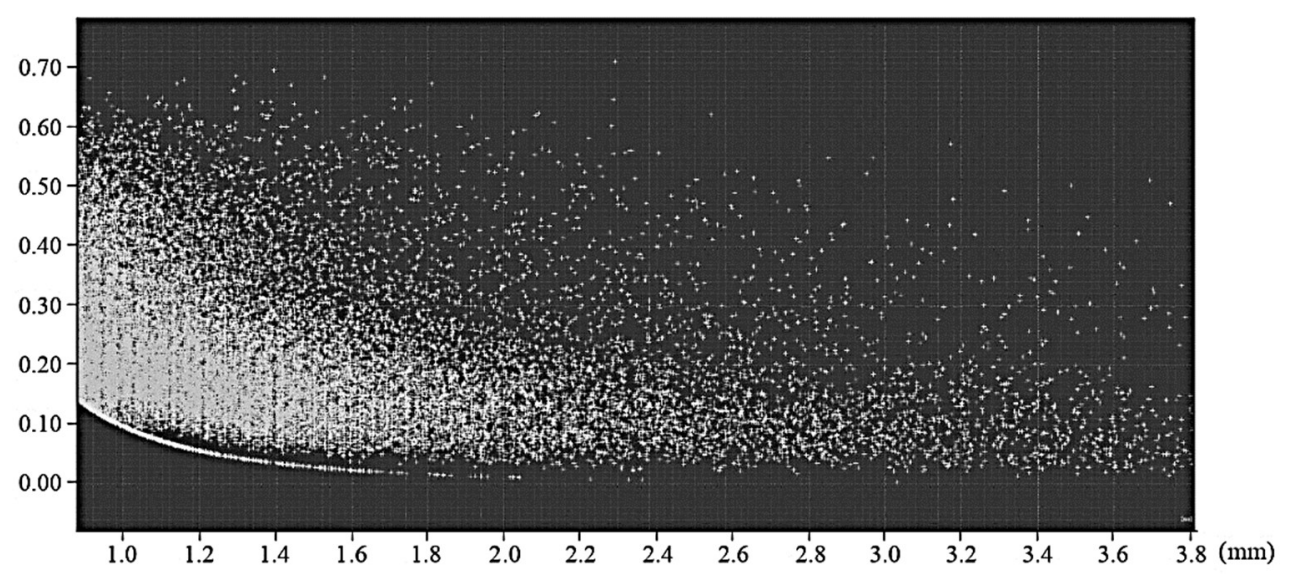

Fig. 3. Diagram «Pore diameter - pore compactness». 


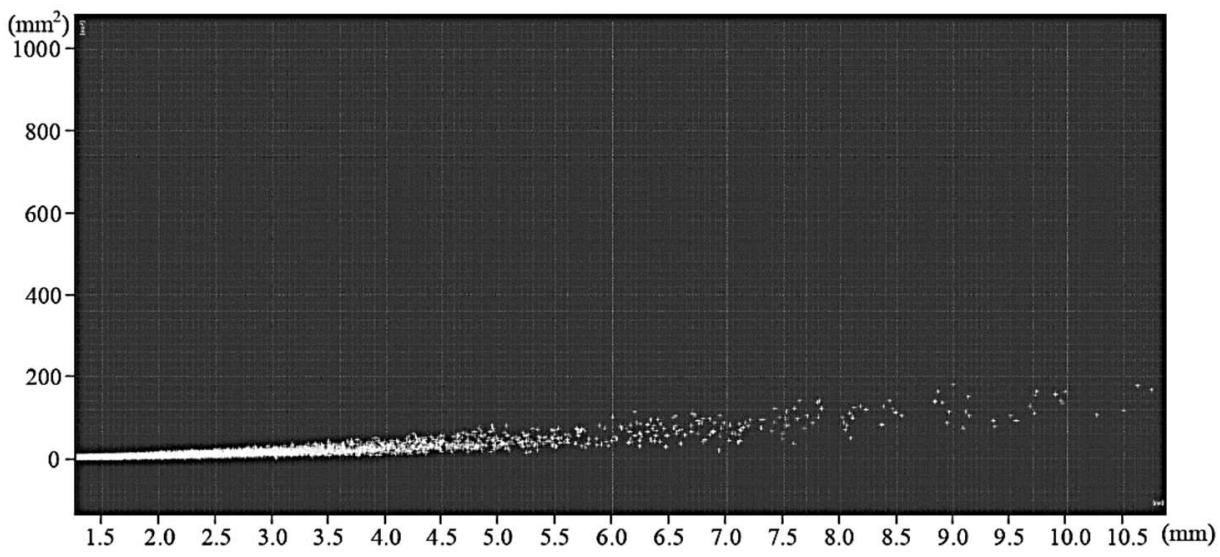

Fig. 4. Diagram «Pore diameter - pore surface area».



Fig. 5. Diagram «Pore diameter - pore volume».

Following method of statistical data processing is planned to be used as a mathematical apparatus for predicting frost resistance functions from correlated technological parameters. The authors propose to use the following method of statistical data processing. Frost resistance value for a certain combination of technological parameters (value of control function at required point) is calculated as weighted from the known frost resistance values at adjacent points, inversely proportional to the distance in the reduced factor space, and is determined by the formula:

$$
Y_{\text {req }}=Y_{0} * \frac{D_{0}}{D_{\Sigma}}+Y_{1} * \frac{D_{1}}{D_{\Sigma}}+Y_{2} * \frac{D_{2}}{D_{\Sigma}}
$$

where $Y_{\text {req }}$ - the predicted value of frost resistance from the required combination of technological parameters (the predicted value of the control function at the required point of the reduced factor space);

$\mathrm{D}_{\mathrm{i}}$ - distance in the represented factor space from point «i $\rangle$ to the required point.

The factor space must be reduced to a unit space in order to ensure the possibility of considering indicators with significantly different scales as parameters.

Each term in the formula corresponds to the product of previously experimentally obtained value of frost resistance (control function) with a specific combination of technological parameters (at point «i» of the factor space) - by the specific weight of this point. 
Thus, the more distant the known points are from the required one, the less weight is assigned to the function value at this point during forecasting. Using this algorithm will reduce the database required for forecasting and identify the most significant parameters. As a result, it is necessary to determine the most effective combination of technological parameters.

\section{Conclusions}

1. Based on the experimental and theoretical studies performed by the authors possibility of obtaining concretes with frost resistance level $\left(\mathrm{F}_{2} 200\right)$ higher than aggregate frost resistance level $\left(F_{1} 150\right)$ has been shown. These indicators are achieved due to the rational combination of air-entraining and plasticizing additives.

2. The evaluation of the qualitative analysis of the diagrams in the aspect of assessing the influence of the nature of the pores on the frost resistance indicators of the developed compositions is of considerable interest for further research. Revealing these regularities will make it possible to determine the method of the most effective air entrainment, corresponding to the maximum combinations of frost resistance and strength. The identification of patterns is assumed in the format of constructing regression models and other methods that provide a linkage of correlated parameters to varying degrees.

\section{References}

1. T. Petrova, E. Chistyakov, Y. Makarov. Methods of road surface durability improvement, Transportation Research Procedia 36, 586-590 (2018). DOI: 10.1016/j.trpro.2018.12.149.

2. A. Garipov, D. Makarov, V. Khozin, S. Stepanov, D. Ayupov. Cement concrete modified by fine-dispersed anionactive bitumen emulsion for road construction, IOP Conference Series: Materials Science and Engineering 890, (2020). DOI: 10.1088/1757-899X/890/1/ 012107.

3. M. Kosukhin, A. Kosukhin. The Modified Composite Binder for Cement-Concrete Road Surfaces, IOP Conference Series: Materials Science and Engineering 463, (2018). DOI: $10.1088 / 1757-899 X / 463 / 4 / 042036$.

4. R. Mukhametrakhimov, I. Aliullova. Improvement of the quality control system for expansion joints with rubber compensators during the repair of bridge constructions, Izvestiya KGASU 53, (2020).

5. Y. Gao, X. Li, K. Dai, X. Yu, J. Yuan. Anti-icing Technology and Effectiveness Evaluation of Super-hydrophobic Bionic Cement Concrete Pavement, Cailiao Daobao/Materials Review 31, 132-137 (2017). DOI: 10.11896/j.issn.1005-023X.2017.014.028.

6. T. Serhij. Research of the reasons of frost destruction of road concrete, Key Engineering Materials 864 KEM, 175-179 (2020). DOI: 10.4028/www.scientific.net/KEM.864.175.

7. N. Morozov, N. Krasinikova, I. Borovskikh. Factors affecting the deterioration of concrete pavement slabs, Magazine of Civil Engineering 59, 30-38 (2015). DOI: 10.5862/MCE.59.3.

8. O. Matveeva, G. Fedorova. Influence of air entrainment content on strength and frost resistance of concrete. in American Concrete Institute, ACI Special Publication 2018June, (2018).

9. L. Alimov, V. Voronin, O. Larsen, V. Korovyakov. Effect of the Structural Characteristics on Frost Resistance of Concrete, Advances in Intelligent Systems and Computing 692, 601-607 (2018). DOI: 10.1007/978-3-319-70987-1_63.

10. D. Smirnov, T. Garaev, T. Sungatullin, A. Lobanova. Development of a mathematical model for optimization of concrete composition, Izvestiya KGASU 54, (2020).

11. D. Smirnov, Z. Kamalova, R. Rahimov. Evaluation of corrosion resistance of steel reinforces in modified concrete, Izvestiya KGASU 29, (2014). 
12. V. Khozin, N. Morozov, S. Stepanov, I. Borovskikh, O. Khokhryakov, H. Muginov, V. Avksentiev. Fine-grained concrete. Patent RF, No. 2473493, (2013).

13. V. Khozin, O. Khokhryakov, R. Nizamov. A «carbon footprint» of low water demand cements and cement-based concrete, IOP Conf. Ser. Mater. Sci. Eng. 890, (2020). DOI: $10.1088 / 1757-899 X / 890 / 1 / 012105$.

14. R. Mukhametrakhimov, L. Lukmanova. Structure and properties of mortar printed on a $3 D$ printer, Magazine of Civil Engineering 102, 10206 (2021). DOI: 10.34910/MCE.102.6.

15. R. Mukhametrakhimov, L. Lukmanova. Influence of the technological properties of cement-sand mortar on the quality of $3 D$ printed products, IOP Conference Series: Materials Science and Engineering 890, (2020). DOI: 10.1088/1757-899X/890/1/012082.

16. L. Mavliev, E. Vdovin, V. Stroganov, N. Konovalov. Road Cement-Mineral Materials with Granulometric and Hydrophobic Additives, Lecture Notes in Civil Engineering 141, 20-28 (2021). DOI: 10.1007/978-3-030-67654-4_3.

17. Y. Bazhenov. Concrete Technology. ASV Publishing House, Moscow, (2011).

18. A. Sheikin, L. Dobshits. Cement concrete of high frost resistance. Stroyizdat, Leningrad, (1989).

19. Y. Song, J. Zhou, Z. Bian, G. Dai. Pore structure characterization of hardened cement paste by multiple methods, Advances in Materials Science and Engineering 2019, (2019). DOI: $10.1155 / 2019 / 3726953$.

20. M. Yio, H. Wong, N. Buenfeld. 3D pore structure and mass transport properties of blended cementitious materials, Cement and Concrete Research 117, 23-37 (2019). DOI: 10.1016/j.cemconres.2018.12.007.

21. J. Yang, P. Zhang. A concise pore structure model for predicting the effective ion diffusion coefficients of cementitious materials, Construction and Building Materials 265, (2020). DOI: 10.1016/j.conbuildmat.2020.120321.

22. K. Yang, C. White. Modeling of aqueous species interaction energies prior to nucleation in cement-based gel systems, Cement and Concrete Research 139, (2021). DOI: 10.1016/j.cemconres.2020.106266.

23. J. Zhang, C. Lin, B. Dong, L. Tang, S. Hong. Inverse modeling deduction of pore distribution in cement materials from capillary absorption features, Cement and Concrete Composites 109, (2020). DOI: 10.1016/j.cemconcomp.2020.103557.

24. T. Powers. Topics in Concrete Technology. 4. Charakteristics of Air Void Systems, Journal of PCA Research and Development Labs, (1965).

25. V. Batrakov, V. Kuntsevich. On the question of the optimal parameters of the system of conditionally closed pores in frost-resistant concretes of increased strength, NIIZHB, Moscow, (1985).

26. O. Kuntsevich. Concrete of high frost resistance for structures of the Far North, Stroyizdat, Leningrad, (1983).

27. Y. Guo, X. Chen, B. Chen, R. Wen, P. Wu. Analysis of foamed concrete pore structure of railway roadbed based on X-ray computed tomography, Construction and Building Materials 273, (2021). DOI: 10.1016/j.conbuildmat.2020.121773.

28. M. Krstic, J. Davalos, E. Rossi, S. Figueiredo, O. Copuroglu. Freeze-thaw resistance and air-void analysis of concrete with recycled glass-pozzolan using X-ray microtomography, Materials 14, 1-26 (2021). DOI: 10.3390/ma14010154. 